\title{
A Method of Determination of Dominant Vibration Periods Values for Nonhomogeneous Multilayer Ground Sites
}

\author{
E.Y.Khachiyan \\ Institute of Geological Sciences National Academy of Sciences, Prosp. Marshala Bagramyana, 24a, Yerevan, 0019, Republic of Armenia \\ *Corresponding Author: edkhach@sci.am
}

Copyright (C) 2013 Horizon Research Publishing All rights reserved.

\begin{abstract}
This paper is presenting development of a method for determination of dominating periods (frequencies) of vibrations of heterogeneous, multilayer foundations. By the method of wave mechanics precise complex transcendent equations of frequencies have been obtained for a foundation of two, three and four layers. To obtain such equations for a foundation having more than four layers is practically impossible. To avoid obtaining such complex frequency equations and to solve such equations using special computer programs a simplified method has been developed in this paper. The main point of the presented method is in successive reduction of a multilayer foundation to two-layer one for which depending upon ratios of amplitudes and periods of vibrations of layers, were computed roots of transcendent equations for more than 5000 combinations of these ratios have been tabulated, extrapolation formula has been derived. The procedure designed for determining values of $\mathrm{T}_{01}$ periods of vibrations for any thickness of $n$ layers is performed in the following sequence. First on the basis of data obtained during well-boring or by other geotechnical methods, according to values of $H_{k}$ thickness, shear waves $v_{s k}$ velocities, shear moduli $G_{k}$ and densities $\rho_{\mathrm{k}}$ of layers are calculated all periods of each layer (as of homogeneous) by the formula $\mathrm{T}_{\mathrm{k}}=4 \mathrm{H}_{\mathrm{k}} / \mathrm{v}_{\mathrm{sk}}$. Next it is regarded that the foundation consists of only two upper layers with their $\mathrm{H}_{1}, \mathrm{H}_{2}$ and $\mathrm{T}_{1}$ and $\mathrm{T}_{2}$. By a special table and a formula the vibration period $\mathrm{T}_{01}^{1-2}$ is calculated. Then two upper layers are regarded as one layer of $\mathrm{H}_{1}+\mathrm{H}_{2}$ thickness and $\mathrm{T}_{01}^{1-2}$ period, and it considered with the third layer of $\mathrm{H}_{3}$ thickness and $\mathrm{T}_{3}$ period. In similar manner by ratio values $\mathrm{H}_{1}+\mathrm{H}_{2}$ and $\mathrm{H}_{3}$ and $\mathrm{T}_{01}^{1-2}$ and $\mathrm{T}_{3}$ a the period $\mathrm{T}_{01}^{1-3}$ of conditional sandwich thickness. This process proceeds for all layers. The obtained at the last stage the value of the period $T_{01}^{1-n}$ is assumed as a sought value of dominated period of the entire thickness of $n$ layers. The method is illustrated be examples and estimation of its error is given.
\end{abstract}

Keywords Multilayer Ground, Dominant Periods,
Precise, Simple, Methods

\section{Introduction}

Fundamental characteristic of compound vibratory motion of ground in earthquakes is a spectrum of their frequencies (periods) depending upon local geological conditions of a building site. They usually have complex geological structure involving conglomerate of silt layers, sand, and gravel comparatively late period (alluvial-deluvial deposits) over more young stratifications. Layers of upper alluvial grounds are much more loose and complex than underlying ground. More dense lower ground is called "ground foundation", and upper layers of sedimentations "superficial layer" or "near-surface thickness". Thus, the basic singularity of alluvial-deluvial grounds is the presence there of complex structures composed of materials having different mechanical properties. In earthquakes this structure has a great influence on behavior of vibration motion of the upper layer of thickness, on which the foundation of a structure rests. It is known that seismic waves in reaching the Earth surface generate in it surface seismic waves. Surface waves propagation velocities in upper layers are less than in lower deep layers. Therefore, according to refraction and reflection rules seismic transversal waves will fall on layers of near-surface thickness of the Earth at almost right angle and inside of the thickness will take place their multiple refraction and reflection. As a result of these phenomena in the Earth's upper layer a more continuous vibration process of definite vibration periods is generated conditioned physical-and-mechanical characteristics and thicknesses all layers of stratum. These periods of vibrations are assumed to refer to as dominant periods of ground vibrations.

Seismic load on structures is of dynamic behavior, hence maximum level of the effect occurs when values of ground vibration and surface structures' free vibrations periods coincide (resonance) or differ slightly. In addition the analysis of earthquake consequences shows that the character and peculiarities of damages of buildings and 
structures at the time of earthquakes differ depending on ground conditions. On loose grounds during earthquakes considerable soil settlement, inclination and even overturning of structures are observed and on bedrock ground - cracks in most components of structures, large relative displacements and relative deformations through the entire body of the structure. Thus, ground conditions not only have an influence on kinematic characteristics of seismic load but also essentially change the character of the damage of structures. According to the building norms of earthquake-proof structures building sites in all countries are divided into a number (4-6) of categories - from the most dense to the most loose soils. We believe that in the capacity of integral characteristic while soils are divided into categories according to seismic properties along with other parameters it is reasonable to assume a value of dominant period $\mathrm{T}_{01}$, since physical-and-mechanical characteristics of all layers' thicknesses affect on its formation, as is presented below. A version of such classification of grounds is presented in Table 1 where data have been taken from Earthquake-proof Building Code of the Republic of Armenia [1].

Table 1. The seismic category of a heterogeneous foundation on the basic of the value of its dominating period of vibrations

\begin{tabular}{|c|c|c|}
\hline $\begin{array}{c}\text { Category of } \\
\text { heterogeneous ground } \\
\text { foundations } \\
\text { according to seismic } \\
\text { properties }\end{array}$ & $\begin{array}{c}\text { Value of transverse } \\
\text { waves propagation } \\
\text { average velocity } \overline{\mathrm{V}}_{\mathrm{s}} \\
\text { within entire } \\
\text { heterogeneous } \\
\text { thickness H from } \\
\text { leveling mark to } \\
\text { dense rocks } \\
\overline{\mathrm{V}}_{\mathrm{s}} \geq 800 \mathrm{~m} / \mathrm{s}, \mathbf{m} / \mathbf{s}\end{array}$ & $\begin{array}{c}\text { Value of dominant } \\
\text { period } \mathrm{T}_{01} \text { for all } \\
\text { heterogeneous } \\
\text { thickness } \mathrm{H} \\
\text { from leveling mark to } \\
\text { dense rocks } \\
\mathrm{V}_{\mathrm{s}} \geq 800 \mathrm{~m} / \mathrm{s}, \mathbf{s}\end{array}$ \\
\hline I & $\overline{\mathrm{v}}_{\mathrm{s}}>800$ & $\mathrm{~T}_{01} \leq 0.3$ \\
\hline II & $500<\overline{\mathrm{V}}_{\mathrm{s}}<800$ & $0.3<\mathrm{T}_{01} \leq 0.6$ \\
\hline III & $150<\overline{\mathrm{v}}_{\mathrm{s}}<500$ & $0.6<\mathrm{T}_{01} \leq 0.8$ \\
\hline IV & $\overline{\mathrm{v}}_{\mathrm{s}}<150$ & \multicolumn{2}{|c|}{$\mathrm{T}_{01}>0.8$} \\
\hline
\end{tabular}

According to [1] in order to avoid resonance phenomena it is necessary to meet the following conditions:

$\mathrm{T}_{01}>1.5 \mathrm{~T}_{1}$ or $1.5 \mathrm{~T}_{1}<\mathrm{T}_{01}$

where $T_{1}$ is the period of the first mode of free vibrations of surface structures, $\mathrm{T}_{01}$-is the first dominant period of ground thickness.

Therefore, while designing new buildings and structures it is necessary reliably forecast not only maximum value of the ground acceleration, but also the value of dominant period of the ground vibration during earthquake.

Reliable data on dominant periods in earthquake can be obtained by registration of acceleration during severe earthquake through its spectral (Fourier) analysis.

Taking into consideration a wide variety of litho logic columns' structures in building sites when designing new building and structures it is difficult to find similar site on which at least one moderate earthquake was registered. Today the most widespread ways for defining values of dominant periods of vibrations are:

- by recording microvibrations on the upper surface of the thickness (building site excavation) and its spectral analysis,

- by solving wave equations of multilayer continuum with respective thicknesses, elasticity and density characteristics established as a consequence of engineering-and-geological survey (well boring) and laboratory research.

This paper concerns development of precise and simplified methods designed for defining dominant periods of multilayer foundation vibration by solving wave equations and comparative analysis of results obtained by applying different methods.

\section{Determination of Free Vibrations Periods of Nonhomogeneous Foundations}

Near-surface no homogeneous strata is considered as continuum composed of $n$ layers with their physical-and-mechanical characteristics: densities $\rho_{\mathrm{k}}$, shear module $G_{k}$, and thicknesses $\mathbf{H}_{\mathbf{k}}$ (Fig.1.) We hold that no homogeneous surface layer of the total thickness $\mathrm{H}$ rests on the "ground of foundation". When vertical propagation of transverse wave there is only one horizontal component $\mathrm{u}(\mathrm{x}, \mathrm{t})$, which inside each layer $\mathrm{u}_{\mathrm{k}}(\mathrm{x}, \mathrm{t})$ must satisfy wave equation. Taking into consideration the fact that viscous properties of the medium have little influence on the periods of free vibrations, they can be ignored and as a wave equation we get [2]

$$
\mathrm{G}_{\mathrm{k}} \frac{\partial^{2} \mathrm{u}_{\mathrm{k}}(\mathrm{x}, \mathrm{t})}{\partial \mathrm{x}^{2}}-\rho_{\mathrm{k}} \frac{\partial^{2} \mathrm{u}_{\mathrm{k}}(\mathrm{x}, \mathrm{t})}{\partial \mathrm{t}^{2}}, \mathbf{k}=\mathbf{1}, \mathbf{2}, \ldots, \mathbf{n}
$$

For further simplification of the problem, let us numerate the layers starting from the top layer, take the origin of coordinates on the earth's surface and assume designations:

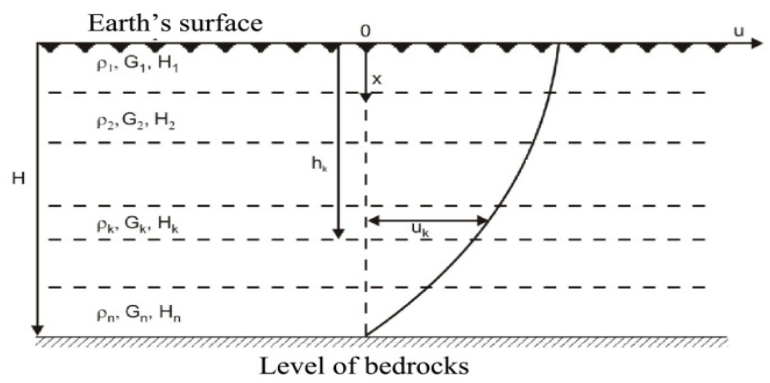

Figure 1. Design diagram of the non-homogeneous multilayer bedding

$$
\mathrm{h}_{\mathrm{k}}=\sum_{\mathrm{i}-0}^{\mathrm{k}} \mathrm{H}_{\mathrm{i}}, \mathrm{h}_{0}=0, \mathrm{~h}_{1}=\mathrm{H}_{1}, \mathrm{~h}_{\mathrm{n}}=\mathrm{H}
$$

The general solution of (1) is given by

$$
\begin{gathered}
\mathrm{u}_{\mathrm{k}}(\mathrm{x}, \mathrm{t})=\sum_{\mathrm{i}=1}^{\infty} \mathrm{u}_{\mathrm{ki}}(\mathrm{x}) \cdot \sin \mathrm{p}_{\mathrm{i}} \mathrm{t}, \quad \mathrm{k}=1,2, \ldots, \mathrm{n} \\
\mathrm{h}_{\mathrm{k}-1} \leq \mathrm{x} \leq \mathrm{h}_{\mathrm{k}}
\end{gathered}
$$


where $\mathrm{p}_{\mathrm{i}}$ is sought-for angular frequency $\mathrm{i}$-th mode of free vibrations of the surface non-homogeneous multilayer bedding, $u_{k}(x, t)$ is shear strain of $k$-th layer of $i$-th mode. Substituting (3) in (2) for a partial solution of $\mathrm{u}_{\mathrm{ki}}(\mathrm{x})$, we have

$$
\mathrm{u}_{\mathrm{ki}}^{\prime \prime}(\mathrm{x})+\lambda_{\mathrm{ki}}^{2} \cdot \mathrm{u}_{\mathrm{ki}}(\mathrm{x})=0, \quad \mathrm{i}=1,2, \ldots, \mathrm{n}
$$

where

$$
\lambda_{\mathrm{ki}}^{2}=\frac{\mathrm{p}_{\mathrm{i}}^{2} \rho_{\mathrm{k}}}{\mathrm{G}_{\mathrm{k}}}
$$

Solution of (4) is sought-for in the form

$$
\begin{aligned}
& \mathrm{u}_{\mathrm{ki}}(\mathrm{x})=\mathrm{A}_{\mathrm{ki}} \sin \lambda_{\mathrm{ki}} \mathrm{x}+\mathrm{B}_{\mathrm{ki}} \cos \lambda_{\mathrm{ki}} \mathrm{x} \\
& \mathrm{h}_{\mathrm{k}-1}<\mathrm{x} \leq \mathrm{h}_{\mathrm{k}} \\
& \mathrm{k}=1,2, \ldots, \mathrm{n},
\end{aligned}
$$

To determine $2 \mathrm{n} \quad \mathrm{A}_{\mathrm{ki}}$ and $\mathrm{B}_{\mathrm{ki}}$ factors and angular frequency $\mathrm{p}$ we get the following two boundary conditions

$$
\begin{array}{ll}
\text { when } \mathrm{x}=0 & \mathrm{u}_{1}^{\prime}(0)=0, \\
\text { when } \mathrm{x}=\mathrm{H} & \mathrm{u}_{\mathrm{n}}(\mathrm{H})=0
\end{array}
$$

and $2 n-2$ equality conditions for shear strains and transverse forces on levels of the layers division planes, that is

$$
\begin{gathered}
\mathrm{u}_{\mathrm{ki}}\left(\mathrm{h}_{\mathrm{k}}\right)=\mathrm{u}_{\mathrm{k}+\mathrm{ii}}\left(\mathrm{h}_{\mathrm{k}}\right) \\
\mathrm{G}_{\mathrm{k}} \mathrm{u}_{\mathrm{ki}}^{\prime}\left(\mathrm{h}_{\mathrm{k}}\right)=\mathrm{G}_{\mathrm{k}+\mathrm{u}} \mathrm{u}_{\mathrm{k}+\mathrm{i}}^{\prime}\left(\mathrm{h}_{\mathrm{k}}\right)
\end{gathered}
$$

$$
\mathrm{k}=1,2, \ldots, \mathrm{n}-1
$$

Substituting (6) in boundary conditions (7) and condition of compatibility (8) for $2 n$ unknown coefficients $A_{k i}$ and $B_{k i}$, we have

$$
\begin{gathered}
\mathrm{A}_{\mathrm{li}}=0 \\
\mathrm{~A}_{\mathrm{ni}} \sin \lambda_{\mathrm{ni}} \mathrm{H}+\mathrm{B}_{\mathrm{ni}} \cos \lambda_{\mathrm{ni}} \mathrm{H}=0 \\
\mathrm{~A}_{\mathrm{ki}} \sin \lambda_{\mathrm{ki}} \mathrm{h}_{\mathrm{k}}+\mathrm{B}_{\mathrm{ki}} \cos \lambda_{\mathrm{ki}} \mathrm{h}_{\mathrm{k}}= \\
=\mathrm{A}_{\mathrm{k}+\mathrm{ii}} \sin \lambda_{\mathrm{k}+1 \mathrm{i}} \mathrm{h}_{\mathrm{k}}+\mathrm{B}_{\mathrm{k}+\mathrm{ii}} \cos \lambda_{\mathrm{k}+\mathrm{li}} \mathrm{h}_{\mathrm{k}} \\
\mathrm{A}_{\mathrm{ki}} \mathrm{G}_{\mathrm{k}} \lambda_{\mathrm{ki}} \cos \lambda_{\mathrm{ki}} \mathrm{h}_{\mathrm{k}}- \\
-\mathrm{B}_{\mathrm{ki}} \mathrm{G}_{\mathrm{k}} \lambda_{\mathrm{ki}} \sin \lambda_{\mathrm{ki}} \mathrm{h}_{\mathrm{k}}= \\
\mathrm{A}_{\mathrm{k}+\mathrm{li}} \mathrm{G}_{\mathrm{k}+1} \lambda_{\mathrm{k}+\mathrm{il}} \cos \lambda_{\mathrm{k}+\mathrm{ii}} \mathrm{h}_{\mathrm{k}}- \\
-\mathrm{B}_{\mathrm{k}+\mathrm{li}} \mathrm{G}_{\mathrm{k}+1} \lambda_{\mathrm{k}+\mathrm{li}} \sin \lambda_{\mathrm{k}+\mathrm{ii}} \mathrm{h}_{\mathrm{k}} \\
\mathrm{k}=1,2, \ldots, \mathrm{n}-1
\end{gathered}
$$

Since the set of equations (9) relative to $2 \mathrm{n}$ unknown coefficients $A_{k i}$ and $B_{k i}$ is homogeneous, then their unique non-trivial solution takes place only when the determinant of $2 \mathrm{n}$ order, built up of unknown coefficients from the set of equations (9), is equal to zero. This exactly is the desired complex transcendent partial solution for determination of unknown frequancy $p_{i}$. In case of double-layer foundation it will be a determinant of 4-th order, in case of a sandwich -6-th order, and in case of a six-layer - 12-th.

They having been developed, we get

When $\mathrm{n}=2$

$$
\sqrt{\frac{\rho_{1} G_{1}}{\rho_{2} G_{2}}} \operatorname{tg} \frac{2 \pi}{T_{0}} H_{1} \sqrt{\frac{\rho_{1}}{G_{1}}} \operatorname{tg} \frac{2 \pi}{T_{0}} H_{2} \sqrt{\frac{\rho_{2}}{G_{2}}}-1=0
$$

when $n=3 \quad \sqrt{\frac{\rho_{1} G_{1}}{\rho_{2} G_{2}}} \operatorname{tg} \frac{2 \pi}{T_{0}} \alpha_{1} \operatorname{tg} \frac{2 \pi}{T_{0}} \alpha_{2}+\sqrt{\frac{\rho_{2} G_{2}}{\rho_{3} G_{3}}} \operatorname{tg} \frac{2 \pi}{T_{0}} \alpha_{2} \operatorname{tg} \frac{2 \pi}{T_{0}} \alpha_{3}+\sqrt{\frac{\rho_{1} G_{1}}{\rho_{3} G_{3}}} \operatorname{tg} \frac{2 \pi}{T_{0}} \alpha_{1} \operatorname{tg} \frac{2 \pi}{T_{0}} \alpha_{3}-1=0$

when $\mathrm{n}=4$

$$
\begin{aligned}
& \sqrt{\frac{\rho_{1} G_{1}}{\rho_{1} G_{2}}} \operatorname{tg} \frac{2 \pi}{T_{0}} \alpha_{1} \operatorname{tg} \frac{2 \pi}{T_{0}} \alpha_{2}+\sqrt{\frac{\rho_{1} G_{1}}{\rho_{3} G_{3}}} \operatorname{tg} \frac{2 \pi}{T_{0}} \alpha_{1} \operatorname{tg} \frac{2 \pi}{T_{0}} \alpha_{3}+\sqrt{\frac{\rho_{1} G_{1}}{\rho_{4} G_{4}}} \operatorname{tg} \frac{2 \pi}{T_{0}} \alpha_{1} \operatorname{tg} \frac{2 \pi}{T_{0}} \alpha_{4}+\sqrt{\frac{\rho_{2} G_{2}}{\rho_{3} G_{3}}} \operatorname{tg} \frac{2 \pi}{T_{0}} \alpha_{2} \operatorname{tg} \frac{2 \pi}{T_{0}} \alpha_{3}+ \\
& \sqrt{\frac{\rho_{2} G_{2}}{\rho_{4} G_{4}}} \operatorname{tg} \frac{2 \pi}{T_{0}} \alpha_{2} \operatorname{tg} \frac{2 \pi}{T_{0}} \alpha_{4}+\sqrt{\frac{\rho_{3} G_{3}}{\rho_{4} G_{4}}} \operatorname{tg} \frac{2 \pi}{T_{0}} \alpha_{3} \operatorname{tg} \frac{2 \pi}{T_{0}} \alpha_{4}-\sqrt{\frac{\rho_{1} G_{1} \rho_{3} G_{3}}{\rho_{2} G_{2} \rho_{4} G_{4}}} \operatorname{tg} \frac{2 \pi}{T_{0}} \alpha_{1} \operatorname{tg} \frac{2 \pi}{T_{0}} \alpha_{2} \operatorname{tg} \frac{2 \pi}{T_{0}} \alpha_{3} \operatorname{tg} \frac{2 \pi}{T_{0}} \alpha_{4}-1=0
\end{aligned}
$$


where $\mathrm{T}_{0 \mathrm{i}}=\frac{2 \pi}{\mathrm{p}_{\mathrm{i}}}$ is the period of the multilayer continuum free vibrations at i-th mode, $\alpha_{i}=H_{i} \sqrt{\frac{\rho_{i}}{G_{i}}}$.

Thus, regardless of apparent simplicity of the problem, finding of numerical values of free vibrations frequencies for multilayer foundations is related to major difficulties, which can be successfully handled if only special computer programs are used. The obtained correct transcendental equations enable not only calculate values of the main period, but also periods of high mode of multilayer width vibrations. Since for any k-th layer propagation speed of shear waves is expressed by a formula $\mathrm{v}_{\mathrm{sk}}=\sqrt{\frac{\mathrm{G}_{\mathrm{k}}}{\rho_{\mathrm{k}}}}$

then after their substitution in (10)-(12) they can be expressed also in parameters $\rho_{\mathrm{k}}, \mathrm{v}_{\mathrm{sk}}$, and $\mathrm{H}_{\mathrm{k}}$. For example, for a sandwich foundation (11) is in the form

$$
\begin{aligned}
& \frac{\rho_{1} \mathrm{v}_{\mathrm{S} 1}}{\rho_{2} \mathrm{v}_{\mathrm{S} 2}} \operatorname{tg} \frac{2 \pi \mathrm{H}_{1}}{\mathrm{~T}_{0} \mathrm{v}_{\mathrm{S} 1}} \operatorname{tg} \frac{2 \pi \mathrm{H}_{2}}{\mathrm{~T}_{0} \mathrm{v}_{\mathrm{S} 2}}+ \\
& +\frac{\rho_{2} \mathrm{v}_{\mathrm{S} 2}}{\rho_{3} \mathrm{v}_{\mathrm{S} 3}} \operatorname{tg} \frac{2 \pi \mathrm{H}_{2}}{\mathrm{~T}_{0} \mathrm{v}_{\mathrm{S} 2}} \operatorname{tg} \frac{2 \pi \mathrm{H}_{3}}{\mathrm{~T}_{0} \mathrm{v}_{\mathrm{S} 3}}+ \\
& +\frac{\rho_{1} \mathrm{v}_{\mathrm{S} 1}}{\rho_{3} \mathrm{v}_{\mathrm{S} 3}} \operatorname{tg} \frac{2 \pi \mathrm{H}_{1}}{\mathrm{~T}_{0} \mathrm{v}_{\mathrm{S} 1}} \operatorname{tg} \frac{2 \pi \mathrm{H}_{3}}{\mathrm{~T}_{0} \mathrm{v}_{\mathrm{S} 3}}-1=0 .
\end{aligned}
$$

To reduce computational load and make use of frequency (10), (11), and (12) when there is a good many layers it is possible the whole system in advance to reduce to equivalent two-three-or-four-layer systems of reduced (average) shear waves characteristics velocities $\overline{\mathrm{v}}_{\mathrm{sk}}$, densities $\bar{\rho}_{\mathrm{k}}$, and multilayer continuum $\overline{\mathrm{H}}_{\mathrm{k}}$ and make use of respective transcendental (11), (12). It is recommended to calculate the average parameters by formulas [3]

$$
\bar{v}_{\text {sk }}=\frac{\sum_{i=m}^{j} H_{i}}{\sum_{i=m}^{j} \frac{H_{i}}{v_{s i}}}, \quad \bar{\rho}_{k}=\frac{\sum_{i=m}^{j} H_{i} \rho_{i}}{\sum_{i=m}^{j} H_{i}}, \quad \bar{H}_{k}=\sum_{i=m}^{j} H_{i} .
$$

As is seen from (14), characteristics of k-th layer of the reduced system, calculated by that equation, comprises real characteristics of alternating one another $\mathrm{j}-\mathrm{m}$ number of layers from the sequential number $\mathrm{j}$ to the number $\mathrm{m}$. The alternating $\mathrm{j}-\mathrm{m}$ layers are chosen in such a way, that their real characteristics be closely different one from another. It means that different reduced layers can comprise different quantity of real layers.

\section{Simplified Technique for Determining Periods of Multilayer Foundation}

As is seen from the foregoing, determination of free vibrations periods is impossible without using special computer programs. Below a simplified method is stated for determining the value of the basic period $T_{01}$ of the multilayer bedding free vibration without expansion and use of a $2 \mathrm{n}$ determinant of the system (9). We have made an attempt to solve this problem by sequential reducing of a multilayer system (Fig.1) to a double-layer one (Fig.2).

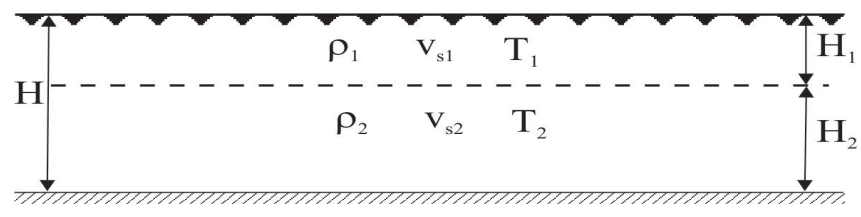

Figure 2. Design diagram of the double-layer bedding

To this end for the two-layer foundation (10) in a transcendental equation the following designations have been taken

$$
\begin{aligned}
& \mathrm{T}_{1}=\frac{4 \mathrm{H}_{1}}{\mathrm{v}_{\mathrm{s} 1}}=4 \mathrm{H}_{1} \sqrt{\frac{\rho_{1}}{\mathrm{G}_{1}}}, \\
& \mathrm{~T}_{2}=\frac{4 \mathrm{H}_{2}}{\mathrm{v}_{\mathrm{s} 2}}=4 \mathrm{H}_{2} \sqrt{\frac{\rho_{2}}{\mathrm{G}_{2}}}
\end{aligned}
$$

where $T_{1}$ and $T_{2}$ are periods of the fundamental tone of free vibrations of the first and second layers, respectively, on the assumption of their independent existence as one-layer foundation, $\mathrm{v}_{\mathrm{sl}}$ and $\mathrm{v}_{\mathrm{s} 2}$ are shear wave velocities.

Taking these designations into consideration (10) can be written in the following form

$$
\operatorname{tg} \frac{\pi}{2} \frac{T_{1}}{T_{0 i}} \cdot \operatorname{tg} \frac{\pi}{2} \frac{T_{2}}{T_{0 i}}=\frac{\rho_{2} H_{2} T_{1}}{\rho_{1} H_{1} T_{2}}
$$

where $T_{0 \mathrm{i}}$ is the period of free vibrations of the entire double-layer system. Designating

$$
\frac{\pi}{2} \frac{\mathrm{T}_{1}}{\mathrm{~T}_{0}}=\theta, \quad \frac{\mathrm{H}_{1}}{\mathrm{H}_{2}}=\alpha, \quad \frac{\mathrm{T}_{1}}{\mathrm{~T}_{2}}=\beta
$$

and assuming $\rho_{1}=\rho_{2}=\rho$ Eq.(14) takes the following form

$$
\operatorname{tg} \theta \cdot \operatorname{tg} \frac{\theta}{\beta}=\frac{\beta}{\alpha}
$$

Therefore the final expression for an unknown period $\mathrm{T}_{0 \mathrm{i}}$ of i-th form will be

$$
\mathrm{T}_{0 \mathrm{i}}=\frac{\pi}{2 \theta_{\mathrm{i}}} \mathrm{T}_{1}
$$

where $\theta_{\mathrm{i}}$ are roots of the transcendental (18) under input parameters $\alpha$ and $\beta$.

To cover all practicaly possible cases of the double-layer bedding roots of (18) have been calculated for the following ranges of $\alpha$ and $\beta$ parameters

$$
0.025 \leq \alpha \leq 100, \quad 0.025 \leq \beta \leq 25
$$

of very small intervals. All in all 91 values for $\alpha$ and 64 values for $\beta$ have been taken, that is all $91 \cdot 64=5824$ roots of (18) have been calculated (of the first three modes of vibrations)

Thus, roots of transcendental equation for 5824 different variants of the double-layer width have actually been calculated. For several variants graphical dependencies $\mathrm{T}_{01} / \mathrm{T}_{1}=\pi / 2 \theta_{1}$ (for the first mode of vibrations) for various $\alpha$ are shown in Fig.3. 

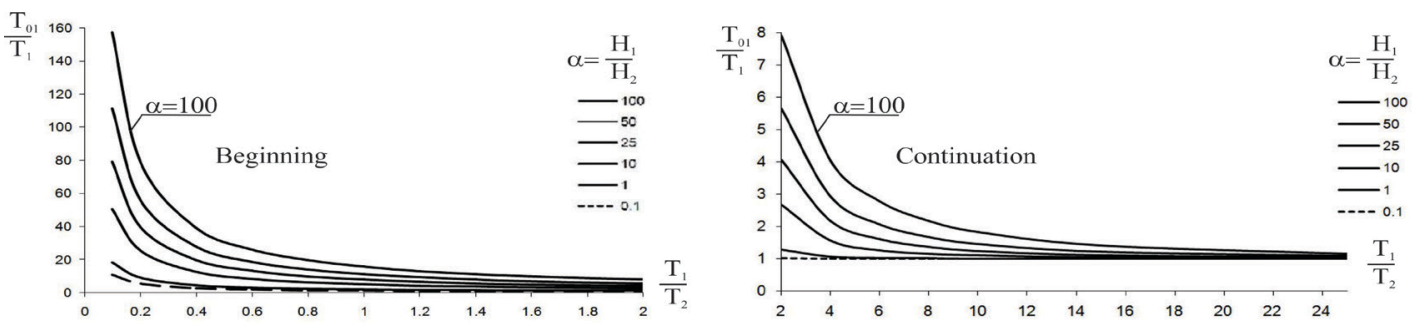

Figure 3. Graphic dependence of the fundamental period of the double-layer foundation, obtained on the basis of frequency (16) solution

Table 2. Values of coefficients $a$ and $b$

\begin{tabular}{|c|c|c|c|c|c|c|c|c|c|c|c|c|c|}
\hline \multirow[b]{2}{*}{$\alpha=\frac{\mathrm{H}_{1}}{\mathrm{H}}$} & \multicolumn{2}{|c|}{$T_{1} / T_{2}<1$} & \multicolumn{2}{|c|}{$1<T_{1} / T_{2}<10$} & \multicolumn{2}{|c|}{$10<T_{1} / T_{2} \leq 25$} & \multirow{2}{*}{$\alpha=\frac{\mathrm{H}_{1}}{\mathrm{H}}$} & \multicolumn{2}{|c|}{$T_{1} / T_{2}<1$} & \multicolumn{2}{|c|}{$1<T_{1} / T_{2}<10$} & \multicolumn{2}{|c|}{$10<T_{1} / T_{2} \leq 25$} \\
\hline & $a_{1}$ & $b_{1}$ & $\mathrm{a}_{2}$ & $\mathrm{~b}_{2}$ & $\mathrm{a}_{3}$ & $\mathrm{~b}_{3}$ & & $a_{1}$ & $b_{1}$ & $\mathrm{a}_{2}$ & $\mathrm{~b}_{2}$ & $\mathrm{a}_{3}$ & $\mathrm{~b}_{3}$ \\
\hline 100 & 15.75 & 0.999 & 15.34 & 0.940 & 5.124 & 0.465 & 1.4 & 2.174 & 0.982 & 1.980 & 0.455 & 1.038 & 0.0111 \\
\hline 90 & 14.94 & 0.999 & 14.52 & 0.934 & 4.636 & 0.438 & 1.3 & 2.116 & 0.982 & 1.926 & 0.439 & 1.035 & 0.0102 \\
\hline 80 & 14.09 & 0.999 & 13.64 & 0.926 & 4.157 & 0.408 & 1.2 & 2.056 & 0.981 & 1.871 & 0.422 & 1.032 & 0.0095 \\
\hline 70 & 13.19 & 0.999 & 12.72 & 0.917 & 3.689 & 0.376 & 1.1 & 1.994 & 0.980 & 1.814 & 0.405 & 1.029 & 0.0086 \\
\hline 60 & 12.38 & 0.98 & 11.73 & 0.906 & 3.235 & 0.339 & 1 & 1.930 & 0.979 & 1.913 & 0.598 & 1.027 & 0.0079 \\
\hline 50 & 11.16 & 0.999 & 10.64 & 0.890 & 2.797 & 0.298 & 0.975 & 1.914 & 0.979 & 1.897 & 0.593 & 1.026 & 0.0077 \\
\hline 25 & 7.937 & 0.998 & 7.335 & 0.811 & 1.799 & 0.172 & 0.95 & 1.898 & 0.978 & 1.880 & 0.587 & 1.025 & 0.0075 \\
\hline 20 & 7.118 & 0.998 & 6.494 & 0.779 & 1.621 & 0.141 & 0.925 & 1.881 & 0.978 & 1.864 & 0.582 & 1.025 & 0.0073 \\
\hline 15 & 6.191 & 0.997 & 5.564 & 0.734 & 1.451 & 0.109 & 0.9 & 1.864 & 0.978 & 1.847 & 0.576 & 1.024 & 0.0071 \\
\hline 10 & 5.098 & 0.996 & 4.478 & 0.662 & 1.290 & 0.075 & 0.875 & 1.847 & 0.978 & 1.831 & 0.571 & 1.023 & 0.0069 \\
\hline 9 & 4.850 & 0.996 & 4.236 & 0.642 & 1.259 & 0.068 & 0.85 & 1.830 & 0.977 & 1.814 & 0.565 & 1.022 & 0.0066 \\
\hline 8.75 & 4.786 & 0.996 & 4.173 & 0.637 & 1.251 & 0.066 & 0.825 & 1.813 & 0.977 & 1.796 & 0.558 & 1.022 & 0.0065 \\
\hline 8.5 & 4.721 & 0.995 & 4.110 & 0.632 & 1.244 & 0.064 & 0.8 & 1.795 & 0.977 & 1.779 & 0.552 & 1.021 & 0.0063 \\
\hline 8.25 & 4.655 & 0.995 & 4.047 & 0.626 & 1.236 & 0.062 & 0.775 & 1.777 & 0.976 & 1.761 & 0.545 & 1.020 & 0.0061 \\
\hline 8 & 4.588 & 0.995 & 3.983 & 0.620 & 1.228 & 0.060 & 0.75 & 1.760 & 0.977 & 1.744 & 0.538 & 1.020 & 0.0059 \\
\hline 7.75 & 4.520 & 0.995 & 3.918 & 0.614 & 1.221 & 0.059 & 0.725 & 1.741 & 0.976 & 1.726 & 0.531 & 1.019 & 0.0057 \\
\hline 7.5 & 4.452 & 0.995 & 3.851 & 0.608 & 1.213 & 0.057 & 0.7 & 1.723 & 0.976 & 1.708 & 0.524 & 1.018 & 0.0055 \\
\hline 7.25 & 4.382 & 0.995 & 3.784 & 0.601 & 1.205 & 0.055 & 0.675 & 1.704 & 0.975 & 1.689 & 0.516 & 1.018 & 0.0053 \\
\hline 7 & 4.311 & 0.995 & 3.717 & 0.594 & 1.198 & 0.053 & 0.65 & 1.686 & 0.975 & 1.671 & 0.508 & 1.017 & 0.0051 \\
\hline 6.75 & 4.239 & 0.995 & 3.648 & 0.587 & 1.191 & 0.051 & 0.625 & 1.667 & 0.975 & 1.652 & 0.500 & 1.016 & 0.005 \\
\hline 6.5 & 4.165 & 0.994 & 3.578 & 0.580 & 1.183 & 0.049 & 0.6 & 1.647 & 0.974 & 1.633 & 0.492 & 1.016 & 0.0047 \\
\hline 6.25 & 4.090 & 0.994 & 3.508 & 0.572 & 1.176 & 0.048 & 0.575 & 1.637 & 0.971 & 1.613 & 0.483 & 1.015 & 0.0045 \\
\hline 6 & 4.014 & 0.994 & 3.442 & 0.594 & 1.169 & 0.046 & 0.55 & 1.608 & 0.974 & 1.594 & 0.473 & 1.014 & 0.0043 \\
\hline 5.75 & 3.937 & 0.994 & 3.458 & 0.602 & 1.161 & 0.044 & 0.525 & 1.590 & 0.973 & 1.574 & 0.464 & 1.014 & 0.0042 \\
\hline 5.5 & 3.857 & 0.994 & 3.382 & 0.593 & 1.154 & 0.042 & 0.5 & 1.567 & 0.973 & 1.554 & 0.454 & 1.013 & 0.004 \\
\hline 5.25 & 3.776 & 0.993 & 3.304 & 0.584 & 1.147 & 0.040 & 0.475 & 1.547 & 0.973 & 1.533 & 0.443 & 1.012 & 0.0038 \\
\hline 5 & 3.694 & 0.993 & 3.331 & 0.635 & 1.139 & 0.038 & 0.45 & 1.525 & 0.972 & 1.516 & 0.446 & 1.012 & 0.0035 \\
\hline 4.75 & 3.609 & 0.993 & 3.145 & 0.563 & 1.132 & 0.036 & 0.425 & 1.504 & 0.972 & 1.491 & 0.421 & 1.011 & 0.0034 \\
\hline 4.5 & 3.523 & 0.992 & 3.051 & 0.551 & 1.125 & 0.034 & 0.4 & 1.482 & 0.972 & 1.469 & 0.409 & 1.010 & 0.0032 \\
\hline 4.25 & 3.434 & 0.992 & 2.979 & 0.541 & 1.118 & 0.033 & 0.375 & 1.460 & 0.971 & 1.447 & 0.396 & 1.010 & 0.003 \\
\hline 4 & 3.342 & 0.992 & 2.894 & 0.528 & 1.110 & 0.031 & 0.35 & 1.437 & 0.971 & 1.424 & 0.382 & 1.009 & 0.0028 \\
\hline 3.75 & 3.249 & 0.991 & 2.898 & 0.575 & 1.103 & 0.029 & 0.325 & 1.414 & 0.971 & 1.401 & 0.368 & 1.008 & 0.0026 \\
\hline 3.5 & 3.152 & 0.991 & 2.805 & 0.561 & 1.096 & 0.027 & 0.3 & 1.390 & 0.971 & 1.378 & 0.353 & 1.008 & 0.0024 \\
\hline 3.25 & 3.053 & 0.990 & 2.710 & 0.545 & 1.089 & 0.025 & 0.275 & 1.366 & 0.971 & 1.353 & 0.337 & 1.007 & 0.0022 \\
\hline 3 & 2.949 & 0.990 & 2.612 & 0.528 & 1.082 & 0.023 & 0.25 & 1.341 & 0.971 & 1.329 & 0.320 & 1.006 & 0.002 \\
\hline 2.75 & 2.843 & 0.989 & 2.512 & 0.510 & 1.075 & 0.021 & 0.225 & 1.315 & 0.971 & 1.303 & 0.301 & 1.006 & 0.0018 \\
\hline 2.5 & 2.731 & 0.988 & 2.408 & 0.490 & 1.068 & 0.019 & 0.2 & 1.289 & 0.971 & 1.276 & 0.281 & 1.005 & 0.0016 \\
\hline 2.25 & 2.617 & 0.987 & 2.398 & 0.557 & 1.061 & 0.017 & 0.175 & 1.261 & 0.972 & 1.267 & 0.305 & 1.004 & 0.0014 \\
\hline 2 & 2.494 & 0.986 & 2.282 & 0.531 & 1.054 & 0.015 & 0.15 & 1.233 & 0.973 & 1.237 & 0.280 & 1.004 & 0.0012 \\
\hline 1.9 & 2.444 & 0.986 & 2.234 & 0.520 & 1.051 & 0.015 & 0.125 & 1.203 & 0.974 & 1.206 & 0.251 & 1.003 & 0.001 \\
\hline 1.8 & 2.392 & 0.985 & 2.185 & 0.508 & 1.049 & 0.014 & 0.1 & 1.172 & 0.975 & 1.173 & 0.218 & 1.002 & 0.0008 \\
\hline 1.7 & 2.340 & 0.984 & 2.135 & 0.496 & 1.046 & 0.013 & 0.075 & 1.139 & 0.977 & 1.137 & 0.181 & 1.002 & 0.0006 \\
\hline 1.6 & 2.284 & 0.984 & 2.084 & 0.483 & 1.043 & 0.012 & 0.05 & 1.103 & 0.981 & 1.098 & 0.136 & 1.001 & 0.0004 \\
\hline 1.5 & 2.231 & 0.983 & 2.032 & 0.469 & 1.040 & 0.0118 & 0.025 & 1.062 & 0.986 & 1.054 & 0.079 & 1.000 & 0.0002 \\
\hline
\end{tabular}


For further lightening of $\mathrm{T}_{01}$ calculation process in practical applications dependence (for the given ratio $\alpha$ ) $\pi / 2 \theta_{1}$ or $T_{01} / T_{1}$ from the ratio $\beta$ was interpolated by exponential function in the form

$$
\frac{\mathrm{T}_{01}}{\mathrm{~T}_{1}}=\mathrm{a}\left(\frac{\mathrm{T}_{1}}{\mathrm{~T}_{2}}\right)^{-\mathrm{b}} \text { or } \mathrm{T}_{01}=\mathrm{aT}\left(\frac{\mathrm{T}_{1}}{\mathrm{~T}_{2}}\right)^{-\mathrm{b}}
$$

Values of constants $a$ and $b$ for various $\alpha$ are presented in Table 2. At that for $T_{1} / T_{2}<1$ it is necessary to take values $a_{1}$ и $b_{1}$ from the table, for $1<T_{1} / T_{2}<1$ - values $a_{2}$ и $b_{2}$, and for $10<\mathrm{T}_{1} / \mathrm{T}_{2} \leq 25$ - values $\mathrm{a}_{3}$ и $\mathrm{b}_{3}$. intermediate values of coefficients $a_{1}, b_{1} ; a_{2}, b_{2} ; a_{3}, b_{3}$ are determined from Table 1 by linear interpretation. We assume $a=1, b=0$ for $T_{1} / T_{2}>25$.

The procedure used for determining values of fundamental period of vibration for any width composed of $n$ layers is performed in the following sequence. At first, by boring data or other geotechnical techniques, on the basis of $\mathrm{H}_{\mathrm{k}}$ layers thicknesses, velocities $v_{s k}$ of shear waves or shear moduli $G_{k}$ and densities $\rho_{\mathrm{k}}$, periods of free vibrations of each layer (as a homogeneous medium) are determined by a formula

$$
\mathrm{T}_{\mathrm{k}}=\frac{4 \mathrm{H}_{\mathrm{k}}}{\mathrm{v}_{\mathrm{sk}}}, \quad \mathrm{k}=1,2,3 \ldots \mathrm{n}
$$

Next, at first it is considered that double-layer bedding consists of only two top layers with their $\mathrm{H}_{1}$ and $\mathrm{H}_{2}, \mathrm{~T}_{1}$ and $T_{2}$. According to the ratio $T_{1} / T_{2}$ for the given ratio $H_{1} / H_{2}$ according to Table 2 values of parameters $a$ and $b$ are determined, and by the formula (20) the period of free vibrations of the conventional double-layer bedding is calculated (from the first two layers). This period is denoted by $\mathrm{T}_{01}{ }^{1-2}$. Then, the two top layers are considered as one equivalent layer of $\mathrm{H}_{1}+\mathrm{H}_{2}$ width and by already calculated period $\mathrm{T}_{01}{ }^{1-2}$ and it, then, is considered with the third layer of $\mathrm{H}_{3}$ thickness and $\mathrm{T}_{3}$ period.

Similarly according to the ratio $\mathrm{T}_{01}^{1-2} / \mathrm{T}_{3}$ and $\left(\mathrm{H}_{1}+\mathrm{H}_{2}\right) / \mathrm{H}_{3}$ from the same Table 2 new values of $a$ and $b$ parameters are determined, and by the same formula (20) ) the period of free vibrations of the conventional three-layer bedding is calculated and denoted $\mathrm{T}_{01}{ }^{1-3}$.

This process is proceeded for all layers. The value $\mathrm{T}_{01}{ }^{1-n}$ of the period obtained at the last stage is the desired value of fundamental period of free vibrations of the entire thickness of $n$ layers. In an another form (with the help of scaling graphs) such an approach was employed in [4]. If at any $\mathrm{k}$-th stage it turns out that $\mathrm{T}_{01}^{1-k} / \mathrm{T}_{\mathrm{k}}>25$, then in the capacity of $\mathrm{T}_{01}^{1-\mathrm{k}}$ the following is assumed

$$
\mathrm{T}_{01}{ }^{1-\mathrm{k}}=\mathrm{T}_{01}{ }^{1-(\mathrm{k}-1)}+\mathrm{T}_{\mathrm{k}}
$$

If amongst layers there is a very thin one having a sequential number $\mathrm{k}$, it can be combined with the next $\mathrm{k}+1$ layer of the reduced thickness $\overline{\mathrm{H}}_{\mathrm{k}}$ and velocity $\overline{\mathrm{v}}_{\mathrm{sk}}$

$$
\overline{\mathrm{H}}_{\mathrm{k}}=\mathrm{H}_{\mathrm{k}}+\mathrm{H}_{\mathrm{k}+1} \quad \overline{\mathrm{v}}_{\mathrm{sk}}=\frac{\mathrm{H}_{\mathrm{k}}+\mathrm{H}_{\mathrm{k}+1}}{\frac{\mathrm{H}_{\mathrm{k}}}{\mathrm{v}_{\mathrm{sk}}}+\frac{\mathrm{H}_{\mathrm{k}+1}}{\mathrm{v}_{\mathrm{sk}+1}}}
$$

In this case the number of layers decreases by a unit.

\section{Examples}

Let us consider two typical examples to illustrate the method. As the first example let us determine the first period of a six-layer section for grounds of Gyumri City, Armenia, with the following parameters $[5,6]$.

$$
\begin{array}{ccc}
\mathrm{H}_{1}=5.5 \mathrm{~m}, & \mathrm{v}_{\mathrm{s} 1}=200 \mathrm{~m} / \mathrm{s}, & \rho_{1}=0.20 \mathrm{t} . \mathrm{s}^{2} / \mathrm{m}^{4} \\
\mathrm{H}_{2}=7.0 \mathrm{~m}, & \mathrm{v}_{\mathrm{s} 2}=300 \mathrm{~m} / \mathrm{s}, & \rho_{2}=0.20 \mathrm{t} . \mathrm{s}^{2} / \mathrm{m}^{4} \\
\mathrm{H}_{3}=12.5 \mathrm{~m}, & \mathrm{v}_{\mathrm{s} 3}=450 \mathrm{~m} / \mathrm{s}, & \rho_{3}=0.21 \mathrm{t} . \mathrm{s}^{2} / \mathrm{m}^{4} \\
\mathrm{H}_{4}=25 \mathrm{~m}, & \mathrm{v}_{\mathrm{s} 4}=350 \mathrm{~m} / \mathrm{s}, & \rho_{4}=0.20 \mathrm{t} . \mathrm{s}^{2} / \mathrm{m}^{4} \\
\mathrm{H}_{5}=100 \mathrm{~m}, & \mathrm{v}_{\mathrm{s} 5}=550 \mathrm{~m} / \mathrm{s}, & \rho_{5}=0.21 \mathrm{t.s} / \mathrm{m}^{4} \\
\mathrm{H}_{6}=200 \mathrm{~m}, & \mathrm{v}_{\mathrm{s} 6}=800 \mathrm{~m} / \mathrm{s}, & \rho_{6}=0.21 \mathrm{t.s} \mathrm{s}^{2} / \mathrm{m}^{4}
\end{array}
$$

Five sequential steps will have the following form

$$
\begin{gathered}
\text { 1) } \mathbf{T}_{1}=\frac{4 \mathbf{H}_{1}}{\mathbf{V}_{\mathrm{s} 1}}=0.11 \quad, \quad \mathbf{T}_{2}=\frac{4 \mathbf{H}_{2}}{\mathbf{V}_{\mathbf{s} 2}}=0.093, \\
\alpha=\frac{\mathbf{H}_{1}}{\mathbf{H}_{2}}=0.785, \quad \boldsymbol{\beta}=\frac{\mathbf{T}_{1}}{\mathbf{T}_{2}}=1.178>1,
\end{gathered}
$$

from Table 2 we find $\mathrm{a}_{2}=1.769, \mathrm{~b}_{2}=0.548$ by formula (20) $\mathrm{T}_{01}^{1-2}=1.76 \times 0.11 \times(1.178)^{-0.548}=0.177 \mathrm{~s}$.

$$
\begin{aligned}
& \text { 2) } \mathrm{T}_{01}{ }^{1-2}=0.177, \quad \mathbf{T}_{\mathbf{3}}=\frac{\mathbf{4} \mathbf{H}_{\mathbf{3}}}{\mathbf{V}_{\mathbf{s} 3}}=0.11, \\
& \alpha=\frac{\mathrm{H}_{1}+\mathrm{H}_{2}}{\mathrm{H}_{3}}=1, \quad \boldsymbol{\beta}=\frac{\mathbf{T}_{\mathbf{0 1}}{ }^{1-2}}{\mathbf{T}_{\mathbf{3}}}=1.6>1,
\end{aligned}
$$

from Table 2 we find $a_{2}=1.913, b_{2}=0.598$ by formula (20) $\mathrm{T}_{01}^{1-3}=1.913 \times 0.177 \times(1.6)^{-0.598}=0.256 \mathrm{~s}$.

$$
\begin{aligned}
& \text { 3) } \mathrm{T}_{01}{ }^{1-3}=0.256, \mathbf{T}_{\mathbf{4}}=\frac{\mathbf{4} \mathbf{H}_{\mathbf{4}}}{\mathbf{V}_{\mathbf{s} 4}}=0.285, \\
& \alpha=\frac{\mathrm{H}_{1}+\mathrm{H}_{2}+\mathrm{H}_{3}}{\mathrm{H}_{4}}=1, \boldsymbol{\beta}=\frac{\mathbf{T}_{\mathbf{0 1}}{ }^{1-3}}{\mathbf{T}_{\mathbf{4}}}=0.898<1,
\end{aligned}
$$

from Table 2 we find $\mathrm{a} 1=1.930+, \mathrm{b} 1=0.980$ by formula (20)

$\mathrm{T} 011-4=1.930 \times 0.256 \times(0.898)-0.980=0.55 \mathrm{~s}$.

4) $\mathrm{T}_{01}{ }^{1-4}=0.550, \mathbf{T}_{\mathbf{5}}=\frac{\mathbf{4} \mathbf{H}_{\mathbf{5}}}{\mathbf{V}_{\mathbf{s} \mathbf{5}}}=0.727$,
$\alpha=\frac{\mathrm{H}_{1}+\mathrm{H}_{2}+\mathrm{H}_{3}+\mathrm{H}_{4}}{\mathrm{H}_{5}}=0.5, \boldsymbol{\beta}=\frac{\mathbf{T}_{\mathbf{0 1}}{ }^{1-4}}{\mathbf{T}_{\mathbf{5}}}=0.756<1$,

from Table 2 we find $\mathrm{a}_{1}=1.567, \mathrm{~b}_{1}=0.973$ by formula (20) $\mathrm{T}_{01}{ }^{1-5}=1.567 \times 0.550 \times(0.756)^{-0.973}=1.131 \mathrm{~s}$.

5) $\mathrm{T}_{01}{ }^{1-5}=1.131, \mathbf{T}_{6}=\frac{\mathbf{4} \mathbf{H}_{6}}{\mathbf{V}_{\mathrm{s} 6}}=1$,

$\alpha=\frac{\mathrm{H}_{1}+\mathrm{H}_{2}+\mathrm{H}_{3}+\mathrm{H}_{4}+\mathrm{H}_{5}}{\mathrm{H}_{6}}=0.75, \boldsymbol{\beta}=\frac{\mathbf{T}_{\mathbf{0 1}}{ }^{1-5}}{\mathbf{T}_{\mathbf{6}}}=1.131>1$,

from Table 2 we find $\mathrm{a}_{2}=1.744, \mathrm{~b}_{2}=0.538$ by formula (20) $\mathrm{T}_{01}{ }^{1-6}=1.744 \times 1.131 \times(1.131)^{-0.538}=1.846 \mathrm{~s}$. 
Finally we have

$\mathrm{T}_{01}{ }^{1-6}=\mathrm{T}_{01}=1.846 \mathrm{~s}$.

As a second example cited below are sequential operations for calculation $\mathrm{T}_{01}$ for 14-layer section Alameda Park in Mexico City with the following parameters [7].

$$
\begin{aligned}
& \mathrm{H}_{1}=5.5 \mathrm{~m}, \quad \mathrm{v}_{\mathrm{s} 1}=76.9 \mathrm{~m} / \mathrm{s}, \quad \rho_{1}=0.169 \mathrm{t.} \mathrm{s}^{2} / \mathrm{m}^{4} \\
& \mathrm{H}_{2}=3.6 \mathrm{~m}, \quad \mathrm{v}_{\mathrm{s} 2}=114.4 \mathrm{~m} / \mathrm{s}, \quad \rho_{2}=0.153 \mathrm{t.} \mathrm{s}^{2} / \mathrm{m}^{4} \\
& \mathrm{H}_{3}=6.6 \mathrm{~m}, \quad \mathrm{v}_{\mathrm{s} 3}=48.5 \mathrm{~m} / \mathrm{s}, \quad \rho_{3}=0.119 \mathrm{t. \textrm {s } ^ { 2 }} / \mathrm{m}^{4} \\
& \mathrm{H}_{4}=0.7 \mathrm{~m}, \quad \mathrm{v}_{\mathrm{s} 4}=62.3 \mathrm{~m} / \mathrm{s}, \quad \rho_{4}=0.18 \mathrm{t.s} / \mathrm{m}^{4} \\
& \mathrm{H}_{5}=3.3 \mathrm{~m}, \quad \mathrm{v}_{\mathrm{s} 5}=55.2 \mathrm{~m} / \mathrm{s}, \quad \rho_{5}=0.118 \mathrm{t.} \mathrm{s}^{2} / \mathrm{m}^{4} \\
& \mathrm{H}_{6}=3.38 \mathrm{~m}, \quad \mathrm{v}_{\mathrm{s} 6}=61.0 \mathrm{~m} / \mathrm{s}, \quad \rho_{6}=0.126 \mathrm{t.s}^{2} / \mathrm{m}^{4} \\
& \mathrm{H}_{7}=3.55 \mathrm{~m}, \quad \mathrm{v}_{\mathrm{s} 7}=62.5 \mathrm{~m} / \mathrm{s}, \quad \rho_{7}=0.12 \mathrm{t} . \mathrm{s}^{2} / \mathrm{m}^{4} \\
& \mathrm{H}_{8}=7.0 \mathrm{~m}, \quad \mathrm{v}_{\mathrm{s} 8}=76.7 \mathrm{~m} / \mathrm{s}, \quad \rho_{8}=0.122 . \mathrm{s}^{2} / \mathrm{m}^{4} \mathrm{~m}^{4} \\
& \mathrm{H}_{9}=1.9 \mathrm{~m}, \quad \mathrm{v}_{\mathrm{s} 9}=77.7 \mathrm{~m} / \mathrm{s}, \quad \rho_{9}=0.119 \mathrm{t.} \mathrm{s}^{2} / \mathrm{m}^{4} \\
& \mathrm{H}_{10}=4.4 \mathrm{~m}, \quad \mathrm{v}_{\mathrm{s} 10}=148.9 \mathrm{~m} / \mathrm{s}, \quad \rho_{10}=0.18 \mathrm{t.} \mathrm{s}^{2} / \mathrm{m}^{4} \\
& \mathrm{H}_{11}=3.35 \mathrm{~m}, \quad \mathrm{v}_{\mathrm{s} 11}=87.0 \mathrm{~m} / \mathrm{s}, \quad \rho_{11}=0.129 \mathrm{t.} \mathrm{s}^{2} / \mathrm{m}^{4} \\
& \mathrm{H}_{12}=0.4 \mathrm{~m}, \quad \mathrm{v}_{\mathrm{s} 12}=105.9 \mathrm{~m} / \mathrm{s}, \quad \rho_{12}=0 . \mathrm{t}^{2} \mathrm{~s}^{2} / \mathrm{m}^{4} \\
& \mathrm{H}_{13}=3.3 \mathrm{~m}, \quad \mathrm{v}_{\mathrm{s} 13}=93.8 \mathrm{~m} / \mathrm{s}, \quad \rho_{13}=0.127 \mathrm{t} . \mathrm{s}^{2} / \mathrm{m}^{4} \\
& \mathrm{H}_{14}=2.45 \mathrm{~m}, \quad \mathrm{v}_{\mathrm{s} 14}=138.4 \mathrm{~m} / \mathrm{s}, \quad \rho_{14}=0.13 \mathrm{t} . \mathrm{s}^{2} / \mathrm{m}^{4}
\end{aligned}
$$

Sequence of the first 1, 2, 3 and subsequent 12,13 steps is presented below

1) $\mathrm{T}_{1}=\frac{4 \mathbf{H}_{1}}{\mathbf{V}_{\mathrm{s} 1}}=0.286, \mathrm{~T}_{2}=\frac{4 \mathrm{H}_{2}}{\mathbf{V}_{\mathrm{s} 2}}=0.125$,

$\alpha=\frac{\mathbf{H}_{1}}{\mathbf{H}_{2}}=1.527, \boldsymbol{\beta}=\frac{\mathbf{T}_{1}}{\mathbf{T}_{\mathbf{2}}}=2.272$,

from Table $2 \mathrm{a}_{2}=2.05, \mathrm{~b}_{2}=0.47$ by formula (20)

$\mathrm{T}_{01}^{1-2}=2.05 \times 0.286 \times(2.272)^{-0.47}=0.398 \mathrm{~s}$.

2) $\mathrm{T}_{01}{ }^{1-2}=0.398, \mathbf{T}_{3}=\frac{\mathbf{4} \mathbf{H}_{3}}{\mathbf{V}_{\mathrm{s} 3}}=0.544$,

$\alpha=\frac{\mathrm{H}_{1}+\mathrm{H}_{2}}{\mathrm{H}_{3}}=1.378, \boldsymbol{\beta}=\frac{\mathbf{T}_{\mathbf{0}_{1}}{ }^{1-2}}{\mathbf{T}_{3}}=0.732$,

from Table $2 \mathrm{a}_{1}=2.17, \mathrm{~b}_{1}=0.982$ by formula (20)

$\mathrm{T}_{01}^{1-3}=2.17 \times 0.398 \times(0.732)^{-0.982}=1.155 \mathrm{~s}$.

3) $\mathrm{T}_{01}^{1-3}=1.155, \mathrm{~T}_{4}=\frac{\mathbf{4} \mathbf{H}_{4}}{\mathbf{V}_{\mathrm{s4}}}=0.044$,

$\alpha=\frac{\mathrm{H}_{1}+\mathrm{H}_{2}+\mathrm{H}_{3}}{\mathrm{H}_{4}}=22.428, \boldsymbol{\beta}=\frac{\mathbf{T}_{\mathbf{0 1}}{ }^{1-3}}{\mathbf{T}_{4}}=25.966>25$,

we assume $\mathrm{T}_{01}{ }^{1-4}=\mathrm{T}_{01}{ }^{1-3}+\mathrm{T}_{4}=1.155+0.044=1.200 \mathrm{~s}$.

12) $\mathrm{T}_{01}{ }^{1-12}=2.258, \quad \mathrm{~T}_{13}=\frac{\mathbf{4} \mathbf{H}_{13}}{\mathbf{V}_{\mathrm{s} 13}}=0.140$,
$\alpha=\frac{\mathrm{H}_{1}+\mathrm{H}_{2}+\mathrm{H}_{3}+\mathrm{H}_{4}+\mathrm{H}_{5}+\mathrm{H}_{6}}{\mathrm{H}_{13}}+$

$+\frac{\mathrm{H}_{7}+\mathrm{H}_{8}+\mathrm{H}_{9}+\mathrm{H}_{10}+\mathrm{H}_{11}+\mathrm{H}_{12}}{\mathrm{H}_{13}}=12.682$,

$\boldsymbol{\beta}=\frac{\mathbf{T}_{\mathbf{0 1}}{ }^{1-12}}{\mathbf{T}_{\mathbf{1 3}}}=16.052>10$,

from Table $2 \mathrm{a}_{3}=1.376, \mathrm{~b}_{3}=0.093$ by formula (20)

$\mathrm{T}_{01}{ }^{1-13}=1.376 \times 2.258 \times(16.052)^{-0.093}=2.397 \mathrm{~s}$.

13) $\mathrm{T}_{01}{ }^{1-13}=2.397, \mathbf{T}_{14}=\frac{\mathbf{4} \mathbf{H}_{14}}{\mathbf{V}_{\mathbf{s} 14}}=0.070$,

$\alpha=\frac{\mathrm{H}_{1}+\mathrm{H}_{2}+\mathrm{H}_{3}+\mathrm{H}_{4}+\mathrm{H}_{5}+\mathrm{H}_{6}}{\mathrm{H}_{14}}+$

$+\frac{\mathrm{H}_{7}+\mathrm{H}_{8}+\mathrm{H}_{9}+\mathrm{H}_{10}+\mathrm{H}_{11}+\mathrm{H}_{12}+\mathrm{H}_{13}}{\mathrm{H}_{14}}=8.428$,

$\boldsymbol{\beta}=\frac{\mathbf{T}_{\mathbf{0 1}}{ }^{1-13}}{\mathbf{T}_{\mathbf{1 4}}}=33.863>25$,

Finally we have

$$
\mathrm{T}_{01}^{1-14}=\mathrm{T}_{01}^{1-13}+\mathrm{T}_{14}=2.3978+0.070=2.468 \mathrm{~s} \text {. }
$$

Comparative analysis of fundamental period $\mathrm{T}_{01}$ values for seven different sections obtained by transcendental equations and suggested method are presented in Table 3.

The above tabulated data prove that the suggested simplified technique provides satisfactory accuracy in calculation of the first period of a nonhomogeneous multilayer foundation, eliminating expansion of high order determinants, for deriving complicated transcendental equations and their solutions using special computer programs and computer.

\section{High Order Periods of Anon homogeneous Foundation}

In homogeneous near-surface layer the nature of high mode vibrations differs from the fundamental mode by odd numbers $3,5,7 \ldots 2 \mathrm{n}-1$. A natural question can be raised what is the range of these ratios variation in case of no homogeneous sections. In the general case to give a reasonable answer is quite difficult. Therefore, we confine the study of this problem theto double-layer section with a large range of characteristic layers' variation (Fig.2). We assume that the obtained results somehow can also be used for multilayer sections.

Besides, we have limited our research within $\mathrm{T}_{02}$ и $\mathrm{T}_{03}$ values of periods of vibrations second and third modes. As an initial transcendental equation for determining $\mathrm{T}_{01}, \mathrm{~T}_{02}$, and $\mathrm{T}_{03}$ (18) was used for large variations of $\alpha=\mathrm{H}_{1} / \mathrm{H}_{2}$ and $\beta=\mathrm{T}_{1} / \mathrm{T}_{2}$ values.

Values of $T_{01} / T_{02}$ and $T_{01} / T_{03}$ are listed in Table 4 respectively when shear waves velocity $\mathrm{v}_{\mathrm{S} 2}$ of the second-lower layer is constant and equal to $800 \mathrm{~m} / \mathrm{s}$, and velocities $v_{\mathrm{S} 1}$ of the first-higher layer varies within $50 \mathrm{~m} / \mathrm{s}$ to $700 \mathrm{~m} / \mathrm{s}$ in different ratios of the first layer $\mathrm{H}_{1}$ thickness to the total $\mathrm{H}$ thickness. Similar results, when $\mathrm{v}_{\mathrm{S} 1}$ is constant and equal to $800 \mathrm{~m} / \mathrm{s}$, and $\mathrm{v}_{\mathrm{S} 2}$ varies from $50 \mathrm{~m} / \mathrm{s}$ to $700 \mathrm{~m} / \mathrm{s}$ are shown in Table 5. 
Table 3. Deviation of $T_{01}$ exact and approximate values

\begin{tabular}{|c|c|c|c|c|c|c|c|c|}
\hline \multirow[b]{2}{*}{$\mathrm{NN}$} & \multirow[b]{2}{*}{ Location } & \multirow{2}{*}{$\begin{array}{l}\text { Number of } \\
\text { layers }\end{array}$} & \multirow{2}{*}{$\begin{array}{c}\text { Total } \\
\text { height } \\
\mathrm{H}, \mathrm{m}\end{array}$} & \multicolumn{3}{|c|}{ Values of $T_{01}, \quad s$. } & \multicolumn{2}{|c|}{$\begin{array}{l}\text { Experimental values } \\
\mathrm{T}_{01}, \mathrm{~s} \text {. }\end{array}$} \\
\hline & & & & $\begin{array}{c}\text { By transcendental } \\
\text { equations } \\
(10)-(12)\end{array}$ & $\begin{array}{l}\text { By simplified } \\
\text { technique }\end{array}$ & $\begin{array}{l}\text { Deviation, } \\
\quad \%\end{array}$ & By microseisms & $\begin{array}{l}\text { By records of } \\
\text { real accelo- } \\
\text { grams }\end{array}$ \\
\hline 1 & El-Centro & 2 & 32 & 0.785 & 0.745 & 5.1 & - & 0.6 \\
\hline 2 & Vanadzor & 3 & 100 & 0.441 & 0.461 & 4.5 & $0.34-0.57$ & - \\
\hline 3 & Ghukasyan & 4 & 35.5 & 0.463 & 0.482 & 4.1 & - & $0.43-0.45$ \\
\hline 4 & California & 4 & 183 & 1.585 & 1.606 & 1.3 & - & - \\
\hline 5 & $\begin{array}{c}\text { Gyumri, } \\
\text { (Marmashen) }\end{array}$ & $5(\overline{4})$ & 350 & 0.428 & 0.474 & 1.2 & - & - \\
\hline 6 & $\begin{array}{l}\text { Gyumri, } \\
\text { (centre) }\end{array}$ & $6(\overline{4})$ & 40 & 1.896 & 1.846 & 9.7 & $1.5-2.5$ & 2.0 \\
\hline 7 & Mexico & $14(4)$ & 48 & 2.402 & 2.468 & 2.7 & - & $2.4-2.6$ \\
\hline 8 & $\begin{array}{l}\text { Arm NPS, } \\
\text { Metsamor }\end{array}$ & 2 & 51 & 0.203 & 0.192 & 5.4 & 0.22 & 0.24 \\
\hline
\end{tabular}

Table 4. Values of ratios $T_{01} / T_{02}$ and $T_{01} / T_{03}$ when $\mathbf{v}_{\mathbf{S 2}}=\mathbf{8 0 0} \mathrm{m} / \mathrm{s}$

\begin{tabular}{|c|c|c|c|c|c|c|c|c|c|c|c|}
\hline $\begin{array}{l}\mathbf{v}_{\mathbf{S 1}} \\
\mathrm{m} / \mathrm{sK}\end{array}$ & $\frac{\mathbf{H}_{1}}{\mathbf{H}}$ & 0.1 & 0.2 & 0.3 & 0.4 & 0.5 & 0.6 & 0.7 & 0.8 & 0.9 & 1 \\
\hline \multirow{2}{*}{50} & $\mathrm{~T}_{01} / \mathrm{T}_{02}$ & 1.88 & 2.96 & 3.05 & 3 & 3.02 & 3.00 & 2.95 & 2.99 & 3.12 & 3 \\
\hline & $\mathrm{T}_{01} / \mathrm{T}_{03}$ & 3.15 & 5.15 & 5.07 & 4.94 & 4.99 & 5.00 & 4.92 & 5.10 & 5.10 & 5 \\
\hline \multirow{2}{*}{100} & $\mathrm{~T}_{01} / \mathrm{T}_{02}$ & 1.54 & 3.27 & 2.87 & 2.98 & 2.99 & 3.00 & 3 & 3.00 & 2.99 & 3 \\
\hline & $\mathrm{T}_{01} / \mathrm{T}_{03}$ & 3.48 & 5.27 & 3.73 & 4.77 & 4.98 & 4.99 & 5.00 & 5.00 & 5 & 5 \\
\hline \multirow{2}{*}{150} & $\mathrm{~T}_{01} / \mathrm{T}_{02}$ & 1.99 & 1.77 & 2.39 & 2.87 & 2.97 & 2.98 & 2.99 & 2.99 & 3 & 3 \\
\hline & $\mathrm{T}_{01} / \mathrm{T}_{03}$ & 3.43 & 3.53 & 3.43 & 3.92 & 4.73 & 4.95 & 4.99 & 5 & 5 & 5 \\
\hline \multirow[b]{2}{*}{200} & $\mathrm{~T}_{01} / \mathrm{T}_{02}$ & 2.42 & 1.79 & 2.09 & 2.62 & 2.91 & 2.98 & 2.99 & 3 & 3 & 3 \\
\hline & $\mathrm{T}_{01} / \mathrm{T}_{03}$ & 3.56 & 3.79 & 3.57 & 3.64 & 5.57 & 4.83 & 4.98 & 4.99 & 5 & 5 \\
\hline \multirow{2}{*}{400} & $\mathrm{~T}_{01} / \mathrm{T}_{02}$ & 2.94 & 2.52 & 2.22 & 2.27 & 2.50 & 2.88 & 2.94 & 2.99 & 3 & 3 \\
\hline & $\mathrm{T}_{01} / \mathrm{T}_{03}$ & 4.6 & 4.00 & 4.18 & 4.13 & 4.01 & 4.2 & 4.65 & 4.98 & 5 & 5 \\
\hline \multirow{2}{*}{600} & $\mathrm{~T}_{01} / \mathrm{T}_{02}$ & 2.98 & 2.87 & 2.68 & 2.58 & 2.61 & 2.71 & 2.87 & 2.96 & 3 & 3 \\
\hline & $\mathrm{T}_{01} / \mathrm{T}_{03}$ & 4.9 & 4.56 & 4.47 & 4.56 & 4.54 & 4.46 & 4.57 & 4.82 & 5 & 5 \\
\hline \multirow{2}{*}{700} & $\mathrm{~T}_{01} / \mathrm{T}_{02}$ & 3 & 2.93 & 2.84 & 2.75 & 2.72 & 2.79 & 2.9 & 2.96 & 3 & 3 \\
\hline & $\mathrm{T}_{01} / \mathrm{T}_{03}$ & 5 & 4.77 & 4.67 & 4.74 & 4.70 & 4.67 & 4.70 & 4.88 & 5 & 5 \\
\hline
\end{tabular}

Table 5. Values of ratios $T_{01} / T_{02}$ and $T_{01} / T_{03}$ when $\mathbf{V}_{\mathbf{S 1}}=\mathbf{8 0 0} \mathrm{m} / \mathrm{s}$

\begin{tabular}{|c|c|c|c|c|c|c|c|c|c|c|c|}
\hline $\mathrm{V}_{\mathrm{S} 2}$ & $\frac{\mathbf{H}_{1}}{\mathbf{H}}$ & 0.1 & 0.2 & 0.3 & 0.4 & 0.5 & 0.6 & 0.7 & 0.8 & 0.9 & 1 \\
\hline \multirow{2}{*}{50} & T01/T02 & 3.02 & 3.13 & 3.34 & 3.66 & 4.09 & 4.68 & 5.55 & 6.97 & 10.06 & 3 \\
\hline & T01/T03 & 5.09 & 5.45 & 6.02 & 6.76 & 7.73 & 8.99 & 10.8 & 20.44 & 17.64 & 5 \\
\hline \multirow{2}{*}{100} & T01/T02 & 3.02 & 3.13 & 3.34 & 3.65 & 4.08 & 4.67 & 5.52 & 12.79 & 8.55 & 3 \\
\hline & T01/T03 & 5.09 & 5.45 & 6.01 & 6.75 & 7.70 & 8.96 & 10.71 & 26.57 & 20.8 & 5 \\
\hline \multirow{2}{*}{150} & T01/T02 & 3.02 & 3.13 & 3.34 & 3.65 & 4.07 & 4.64 & 5.46 & 6.65 & 6.13 & 3 \\
\hline & T01/T03 & 5.09 & 5.44 & 6 & 6.73 & 7.67 & 8.87 & 6.65 & 9.51 & 10.22 & 5 \\
\hline \multirow{2}{*}{200} & T01/T02 & 3.02 & 3.12 & 3.33 & 3.63 & 4.04 & 4.60 & 5.35 & 6.06 & 4.87 & 3 \\
\hline & T01/T03 & 5.08 & 5.44 & 5.98 & 6.70 & 11.1 & 8.68 & 8.99 & 8.06 & 9.06 & 5 \\
\hline \multirow{2}{*}{400} & T01/T02 & 3.01 & 3.11 & 3.29 & 3.54 & 6.73 & 4.19 & 4.26 & 6.73 & 3.30 & 3 \\
\hline & T01/T03 & 5.07 & 5.38 & 5.85 & 6.40 & 8.73 & 6.44 & 6.34 & 8.73 & 5.89 & 5 \\
\hline \multirow{2}{*}{600} & T01/T02 & 3.01 & 3.07 & 3.20 & 5.72 & 3.51 & 3.54 & 3.41 & 3.21 & 3.04 & 3 \\
\hline & T01/T03 & 5.05 & 5.27 & 5.57 & 7.72 & 5.61 & 5.56 & 5.71 & 5.59 & 5.18 & 5 \\
\hline \multirow{2}{*}{700} & T01/T02 & 3.00 & 3.05 & 3.14 & 3.24 & 3.30 & 3.29 & 3.2 & 3.09 & 3.01 & 3 \\
\hline & T01/T03 & 5.03 & 5.19 & 5.36 & 5.39 & 5.32 & 5.34 & 5.41 & 5.28 & 5.06 & 5 \\
\hline
\end{tabular}


In both Tables real ratios of periods for variant close to 3 and 5 are separated by gray tone. It is seen from Table 4 that the maximum difference of $\mathrm{T}_{01} / \mathrm{T}_{02}$ and $\mathrm{T}_{01} / \mathrm{T}_{03}$, respectively from 3 and 5 , in increasing direction occurs when under the first heavy stiff layer of $v_{\mathrm{S} 1}=800 \mathrm{~m} / \mathrm{s}$ loose layer of $\mathrm{v}_{\mathrm{S} 2}=50 \div 150 \mathrm{~m} / \mathrm{s}$ and small thickness. The foregoing suggests that in such sections values of periods of the second and third modes of vibrations will be considerably smaller than periods of vibration's fundamental mode, therefore, their effect, as a very high-frequency component of influence, can be neglected.

And vice versa, from Table 4 it is clear that the maximum difference $T_{01} / T_{02}$ and $T_{01} / T_{03}$ from 3 and 5 to the decrease occurs when on a stiff heavy layer of $\mathrm{v}_{\mathrm{S} 2}=800 \mathrm{~m} / \mathrm{s}$ loose layer is located of $\mathrm{v}_{\mathrm{S} 1}=50 \div 150 \mathrm{~m} / \mathrm{s}$ and small thickness $\left(\mathrm{H}_{1} / \mathrm{H}=0.1 \div 0.15\right)$. In this case $\mathrm{T}_{02}$ and $\mathrm{T}_{03}$ will have comparable with $\mathrm{T}_{01}$ values and, therefore, their effect in the total influence cannot be neglected.

As for the value of the period $\mathrm{T}_{01}$ of the fundamental mode, then for its calculation respective correcting coefficients $\mathrm{k}_{1}$ and $\mathrm{k}_{2}$ have been introduced for $\mathrm{H}=30$ meter foundation, which in many countries have been included in seismic building code. These values are tabulated in Tables 6 and 7 , $\mathrm{k}_{1}$ corresponding to the case when $\mathrm{v}_{\mathrm{S} 2}=800 \mathrm{~m} / \mathrm{s}$, and $\mathrm{v}_{\mathrm{S} 1}$ varies within $25 \div 700 \mathrm{~m} / \mathrm{s}$, and $\mathrm{k}_{2}$ corresponding to the case when $\mathrm{v}_{\mathrm{S} 1}=800 \mathrm{~m} / \mathrm{s}$, and $\mathrm{v}_{\mathrm{S} 2}$ varies within $25 \div 700 \mathrm{~m} / \mathrm{s}$.

For hatched variants in Table 6 the influence on T01 exerted by the top layer can be neglected, and for variants in Table 6 the influence on $T_{01}$ exerted by the bottom layer can be neglected.

Computations have shown that in total thickness of multilayer foundation $\mathrm{H}=30 \mathrm{~m}$, values of periods at $\mathrm{v}_{\mathrm{S} 2}=800 \mathrm{~m} / \mathrm{s}$ and $\mathrm{v}_{\mathrm{S} 2}=1000 \mathrm{~m} / \mathrm{s}$ for $\mathrm{H}_{1} / \mathrm{H}>0.4$ slightly differ from each other, therefore, the value $\mathrm{v}_{\mathrm{S}}=1000 \mathrm{~m} / \mathrm{s}$ can be counted as a lower limit for bed rock in determining category of no homogeneous foundation on the basis of seismic properties and using $\mathrm{T}_{01}$ values [1].

Values of $\mathrm{T}_{01}, \mathrm{~T}_{02}, \mathrm{~T}_{03}$ have been experimentally found for a number of Tokyo City area sections [8]. According to Okomoto data central part of Tokyo City territory has been divided by a one-kilometer-net-shaped map. On that map dominant frequencies are indicated at points of lines intersections, established experimentally.

Table 6. Values of coefficients $\mathrm{k}_{1}\left(\mathrm{~T}_{01}=\frac{4 \mathrm{H}}{\mathrm{v}_{\mathrm{S} 2}} \mathrm{k}_{1}, \mathrm{H}=30 \mathrm{~m}, \mathbf{v}_{\mathrm{s} 2}=\mathbf{8 0 0} \mathrm{m} / \mathrm{s}\right)$

\begin{tabular}{|c|c|c|c|c|c|c|c|c|c|c|c|}
\hline $\mathbf{v}_{\mathbf{S} \mathbf{1}}$ & $\frac{\mathbf{H}_{1}}{\mathrm{H} / \mathrm{s}}$ & 0.05 & 0.1 & 0.15 & 0.2 & 0.3 & 0.4 & 0.5 & 0.6 & 0.8 & 0.9 \\
\hline 25 & $\mathrm{k}_{1}$ & 1.63 & 3.22 & 4.82 & 6.42 & 9.61 & 12.40 & 16.02 & 19.19 & 25.38 & 26.88 \\
\hline 50 & $\mathrm{k}_{1}$ & 1.04 & 1.66 & 2.45 & 3.24 & 4.94 & 6.34 & 8.02 & 9.61 & 13.08 & 14.22 \\
\hline 100 & $\mathrm{k}_{1}$ & 1.00 & 1.07 & 1.34 & 1.70 & 2.48 & 3.27 & 4.56 & 4.84 & 6.42 & 7.20 \\
\hline 150 & $\mathrm{k}_{1}$ & 0.99 & 1.01 & 1.09 & 1.27 & 1.73 & 2.24 & 2.75 & 3.26 & 4.30 & 4.81 \\
\hline 200 & $\mathrm{k}_{1}$ & 0.99 & 1.00 & 1.03 & 1.11 & 1.39 & 1.75 & 2.11 & 2.49 & 3.24 & 3.62 \\
\hline 300 & $\mathrm{k}_{1}$ & 0.99 & 0.99 & 1.03 & 1.02 & 1.13 & 1.30 & 1.51 & 1.74 & 2.18 & 2.43 \\
\hline 400 & $\mathrm{k}_{1}$ & 0.99 & 0.99 & 0.99 & 1.00 & 1.04 & 1.13 & 1.25 & 1.39 & 1.69 & 1.84 \\
\hline 500 & $\mathrm{k}_{1}$ & 0.99 & 0.99 & 0.99 & 0.99 & 1.00 & 1.05 & 1.11 & 1.20 & 1.39 & 1.491 \\
\hline 600 & $\mathrm{k}_{1}$ & 0.99 & 0.98 & 0.98 & 0.98 & 0.99 & 1.01 & 1.04 & 1.08 & 1.20 & 1.26 \\
\hline 700 & $\mathrm{k}_{1}$ & 0.99 & 0.98 & 0.98 & 0.98 & 0.98 & 0.98 & 0.98 & 0.98 & 1.07 & 1.10 \\
\hline
\end{tabular}

Table 7. Values of coefficients $\mathrm{k}_{2}\left(\mathrm{~T}_{01}=\frac{4 \mathrm{H}}{\mathrm{v}_{\mathrm{S} 1}} \mathrm{k}_{2}, \mathrm{H}=30 \mathrm{~m}, \mathrm{v}_{\mathrm{s} 1}=\mathbf{8 0 0} \mathrm{m} / \mathrm{s}\right)$

\begin{tabular}{|c|c|c|c|c|c|c|c|c|c|c|c|}
\hline $\begin{array}{c}\mathbf{v}_{\mathbf{S 2}} \\
\mathrm{m} / \mathrm{s}\end{array}$ & $\frac{\mathbf{H}_{\mathbf{1}}}{\mathbf{H}}$ & 0.1 & 0.2 & 0.3 & 0.4 & 0.5 & 0.6 & 0.7 & 0.8 & 0.9 & 0.95 \\
\hline 25 & $\mathrm{k}_{2}$ & 32.3 & 32.4 & 32.15 & 31.5 & 30.3 & 28.4 & 25.72 & 21.9 & 16.1 & 11.6 \\
\hline 50 & $\mathrm{k}_{2}$ & 16.14 & 16.2 & 16.07 & 15.74 & 15.13 & 14.2 & 12.87 & 10.96 & 8.08 & 5.85 \\
\hline 100 & $\mathrm{k}_{2}$ & 8.07 & 8.09 & 8.02 & 7.78 & 7.57 & 7.11 & 6.45 & 5.51 & 4.1 & 3.02 \\
\hline 150 & $\mathrm{k}_{2}$ & 5.38 & 5.04 & 5.36 & 5.25 & 5.06 & 4.76 & 4.33 & 3.71 & 2.8 & 2.12 \\
\hline 200 & $\mathrm{k}_{2}$ & 4.03 & 4.05 & 4.02 & 3.95 & 3.8 & 3.59 & 3.3 & 2.83 & 2.2 & 1.69 \\
\hline 300 & $\mathrm{k}_{2}$ & 2.69 & 2.7 & 2.7 & 2.64 & 2.55 & 2.42 & 2.23 & 1.96 & 1.57 & 1.32 \\
\hline 400 & $\mathrm{k}_{2}$ & 2.02 & 2.03 & 2.02 & 1.99 & 1.93 & 1.85 & 1.72 & 1.55 & 1.31 & 1.17 \\
\hline 500 & $\mathrm{k}_{2}$ & 1.16 & 1.62 & 1.62 & 1.6 & 1.57 & 1.51 & 1.43 & 1.31 & 1.17 & 1.09 \\
\hline 600 & $\mathrm{k}_{2}$ & 1.35 & 1.35 & 1.35 & 1.35 & 1.32 & 1.29 & 1.24 & 1.17 & 1.09 & 1.05 \\
\hline 700 & $\mathrm{k}_{2}$ & 1.15 & 1.16 & 1.17 & 1.16 & 1.15 & 1.14 & 1.11 & 1.08 & 1.04 & 1.02 \\
\hline
\end{tabular}


Table 8. Experimental value of periods and their ratios $T_{01} / T_{02}$ and $T_{01} / T_{03}$ for Tokyo City

\begin{tabular}{|c|c|c|c|c|c|}
\hline \multirow{2}{*}{$\begin{array}{l}\mathrm{NN} \\
\text { node }\end{array}$} & \multicolumn{3}{|c|}{ Frequencies of the firs three modes of vibrations, hertz } & \multicolumn{2}{|c|}{ Ratios } \\
\hline & $\mathrm{f}_{1}=1 / \mathrm{T}_{01}$ & $\mathrm{f}_{2}=1 / \mathrm{T}_{02}$ & $\mathrm{f}_{3}=1 / \mathrm{T}_{03}$ & $\mathrm{f}_{2} / \mathrm{f}_{1} ; \mathrm{T}_{01} / \mathrm{T}_{02}$ & $\mathrm{f}_{3} / \mathrm{f}_{1} ; \mathrm{T}_{01} / \mathrm{T}_{03}$ \\
\hline 1 & 0.6 & 2.0 & 3.5 & 3.3 & 5.8 \\
\hline 2 & 0.6 & 1.9 & 3.2 & 3.1 & 5.3 \\
\hline 3 & 0.5 & 1.5 & 2.5 & 3.0 & 5.0 \\
\hline 4 & 0.6 & 1.7 & 3.0 & 2.8 & 5.0 \\
\hline 5 & 0.5 & 1.7 & 2.3 & 2.8 & 4.6 \\
\hline 6 & 0.6 & 1.8 & 3.1 & 3.0 & 5.1 \\
\hline 7 & 0.5 & 1.4 & 2.4 & 2.8 & 4.8 \\
\hline 8 & 0.6 & 1.7 & 2.6 & 2.8 & 4.3 \\
\hline 9 & 0.6 & 1.8 & 3.0 & 3.0 & 5.0 \\
\hline 10 & 0.8 & 2.5 & 4.3 & 3.1 & 5.3 \\
\hline 11 & 0.8 & 2.3 & 4.0 & 2.8 & 5.0 \\
\hline 12 & 1.1 & 3.2 & - & 2.9 & - \\
\hline 13 & 1.7 & 4.1 & - & 3.0 & - \\
\hline 14 & 1.6 & 4.8 & - & 3.0 & - \\
\hline 15 & 1.4 & 4.5 & - & 2.8 & - \\
\hline \multicolumn{4}{|c|}{ Average value } & 2.9 & 5.02 \\
\hline
\end{tabular}

Analysis of the map shows that for higher located floors (Minato area) presence of one dominant period is typical, and for the central lower located region (Koto region) typical is the presence of several floors of three and more dominant periods. For some nodes obtained values of the second and third modes of vibrations are presented in Table 7 [8], where also presented the results of our computations of their ratios $\mathrm{T}_{01} / \mathrm{T}_{02}$ and $\mathrm{T}_{01} / \mathrm{T}_{03}$.

The above table shows that for 15 nodes the average values of ratios T01/T02 and T01/T03 periods obtained experimentally, are 2.9 and 5.02 respectively, that is are close to the ratios 3 and 5 for homogeneous sections.

\section{Conclusions}

1. An algorithm designed to determine free vibrations periods for arbitrary inhomogeneous foundations with arbitrary number of layers has been developed. For foundations of two, three, and four layers precise transcendent equations for determination of free vibrations' periods have been derived.

2. A simplified method has been developed for defining dominant periods of vibrations of heterogeneous multilayer foundations by their successive reduction to two-layer equivalent systems. For this purpose tables 1 and 3 have been made. An adequate extrapolation formula (20) was suggested. The method is illustrated for two foundations of six layers (Giumry, Armenia) and 14 layers (Mexico). Accuracy estimation in comparison with the precise method of wave mechanics is presented. Obtained deviations are $1.2 \%$ and $2.7 \%$, respectively.

3. For homogeneous foundation the ratio of vibrations higher modes $\mathrm{T}_{01} / \mathrm{T}_{02}, \mathrm{~T}_{01} / \mathrm{T}_{03}$ amounts to 3,5 . The study showed that for a heterogeneous two-layer foundation with $\mathrm{H}_{1} / \mathrm{H} \geq 0.5$ and $\mathrm{v}_{\mathrm{s} 1} / \mathrm{v}_{\mathrm{s} 2} \geq 0.125$, where $\mathrm{H}$ is a common height, the heterogeneous foundation behaves as homogeneous. A small difference of periods $T_{1}, T_{2}, T_{3}$ ratios from homogeneous occur when under the strong rigid first layer a weak loose layer is placed with $\mathrm{v}_{\mathrm{s} 2} / \mathrm{v}_{\mathrm{s} 1} \leq 0.065$ and when $0.3<\mathrm{H}_{1} / \mathrm{H}<0.9$. It means that for such foundations values of second and third modes of vibrations will be far less than the period of first (basic) mode of vibration and therefore their effect, as high-frequency component of influence, can be neglected.

4. The research results have shown that for foundation of common thickness $\mathrm{H}=30 \mathrm{~m}$ values of periods $\mathrm{T}_{01}$ for $\mathrm{v}_{\mathrm{s} 2}=800 \mathrm{~m} / \mathrm{s}$ and $\mathrm{v}_{\mathrm{s} 2}=1000 \mathrm{~m} / \mathrm{s}$ for $\mathrm{H}_{1} / \mathrm{H}>0.4$ differ slightly. It means that the value of $\mathrm{v}_{\mathrm{s}}=800 \mathrm{~m} / \mathrm{s}$ can be considered as the lower limit for rocks assumed as "ledge rocks". 


\section{REFERENCES}

[1] Earthquake Resistent Construction Deign Codes. RABC II-6.02-2006 Republic of Armenia, Yerevan 2009, 52p.

[2] Khachiyan E.Y. On the Dominant Periods of the Ground Vibrations during the Earthquake. Earthquake Engineering. Safety of structures. Moscow, 2000, №4.-C.10-14

[3] Ahmad A.R., Khachian E.Y. The use of various date set to Evaluate Seismic Hazard in Tartous region (Syria). 5th International Symposium on Eastern Mediterranean Geology. The Ssaloniki, Greece, 14-20 Aprill, 2004, vol.11, pp.639-642.

[4] Madera G. Fundamental Period and Amplification of Peak Acceleration in Layered Systems. Research report R70-37, Chapter 2 June 1970. Massachusetts Institute of Technology,
Cambridge, Massachusetts 02139, pp.27-77.

[5] Yegian M.K., Ghahraman V.G. The Armenian Earthquake of December 1988, Northeastem University, Boston, Massachusetts, October, 1992, 216p

[6] Hadjian A.H. The Spitak, Armenian Earthquake of 7 December 1988 - why so much destruction. Soil Dynamics and Earthquake Engineering 12 (1993) 1-24.

[7] Butcher G., Hopkins D., Jury R., Massey W., McKay G., McVerr G. The September 1985 Mexico Earthquakes: Final Report it the New Zealand Reconnaissance Team. Bulletin of the New Zealand Society for Earthquake Engineering, vol.21, N1, March, 1988, pp.3-30.

[8] Okamoto S. Introduction to Earthquake Engineering. University of Tokyo Press, 1973 